\title{
El golpe de Estado de 1973 en Concepción. Violencia política y control social
}

\section{Danny Monsálvez Araneda}

\section{Concepción: Editorial Universidad de Concepción, 2017. 244 páginas.}

En el transcurso de la historia de Chile, "Concepción se ha constituido en una de las zonas geográficas más importantes del país. Desde la guerra de Arauco, como línea fronteriza, en la cual las relaciones hispano-indígenas se constituían en un marco de referencia obligado de toda la región, pasando por su trascendencia durante el periodo independentista y años posteriores, hasta llegar al siglo XX, la región del Biobío, así como el 'Gran Concepción' y la ciudad propiamente tal, han jugado un rol significativo en el proceso sociopolítico nacional" (Monsálvez, 2012: 58). En dicho contexto, la historiadora Alejandra Brito indica que la ciudad de Concepción y su entorno pueden ser examinados y/o estudiados durante el curso del siglo XX sobre la base de tres aspectos fundamentales y significativos para la región. En primer lugar, la fundación de la Universidad de Concepción, constituyendo un polo cultural e intelectual significativo en la zona; en segundo lugar, las relevantes transformaciones sociales, económicas y urbanas desarrolladas por el proceso industrializador de mediados del siglo XX; y, por último, el quiebre producido por el golpe militar de 1973 (Monsálvez, 2012: 58).

Es precisamente en este último punto, el golpe de Estado y sus posteriores consecuencias, en el cual el autor se detiene para dar cuenta específicamente de las acciones de violencia y represión que se desencadenaron una vez producida la intervención militar del martes 11 de septiembre de 1973 en la ciudad de Concepción.

De esta manera, partimos evidenciando que el texto del historiador Danny Monsálvez Araneda constituye un aporte significativo a la historicidad de la ciudad de Concepción de la segunda mitad del siglo XX, debido a la escasa presencia de trabajos que se circunscriban al golpe de Estado de 1973, a la violencia política y al control social en el plano local. La constante en la historiografía chilena tiene relación estrecha con el centralismo, lo que en la práctica ha generado una visión reducida de lo sucedido durante la dictadura cívico-militar en regiones y, a su vez, se ha tendido a homologar lo ocurrido en la ciudad de Santiago con el resto del país. Por consiguiente, esta investigación tiene como principal objetivo, romper con aquella mirada, dejando 
entrever las particularidades que poseen los estudios locales y la factibilidad de estudiar procesos nacionales desde lo regional.

A continuación, detallaremos algunos aportes historiográficos e ideas principales con el fin de invitar a la lectura no solo a los especialistas en el tema o al mundo académico, sino al público en general, tanto aquellos que fueron parte de la historia relatada, los que por algún motivo u otro desconocen lo sucedido en la ciudad de Concepción, como también a las nuevas generaciones.

En la introducción, el autor plantea los aspectos metodológicos y manifiesta la importancia de realizar un análisis sobre el golpe de Estado en Concepción. De esta forma, con respecto al problema de estudio, argumenta que la historia del golpe de Estado de 1973 es una historia en construcción. Si bien, existen abundantes trabajos bien logrados a nivel nacional, Monsálvez aclara que en las regiones aún están en etapas de elaboración, por tal motivo y con el objetivo de subsanar esta falencia busca de alguna manera hacerse cargo de una parte de ella o bien, incentivar a otros investigadores a trabajar dichas temáticas.

Como hipótesis, manifiesta que las altas movilizaciones políticas y sociales que se desarrollaron en la zona de Concepción durante el gobierno de la Unidad Popular conformaron un conjunto de imaginarios y representaciones sociales y políticas que permitieron la configuración de la violencia política y el control social desde el golpe de Estado del martes 11 de septiembre de 1973, convirtiendo a la región en la segunda zona del país con mayores niveles de victimas (p. 22).

De esta forma, Monsálvez argumenta que lo central planteado por la historiografía nacional sobre el periodo estudiado tiene relación, para su trabajo, con el debate acerca de los orígenes de la violencia política en el Chile reciente. De esta manera, infiere que existen dos ideas centrales: en primer lugar, el planteamiento de que surge en los años sesenta, específicamente con el discurso de la izquierda, idea respaldada por los trabajos realizados por Patricia Arancibia, por ejemplo. En segundo lugar, manifiesta que la violencia política estuvo siempre presente en la historia nacional, es decir, que no se circunscribe a lo enunciado en el punto uno, tesis a la cual se ciñen autores como Tomás Moulian, Igor Goicovic, Gabriel Salazar, Felipe Portales, entre otros.

Definido lo anterior, surge la pregunta, ¿por qué estudiar el Gran Concepción? Para eso el autor deja en claro tres puntos centrales: en primer lugar, se debe a que la producción historiográfica en la zona es débil, existiendo un vacío que se hace necesario analizar; en segundo término, que hacia 1973 el Gran Concepción se convirtió en la segunda zona más importante del país 
en ser reprimida por la dictadura, debido a la gran presencia que mantenía la izquierda en la región; y, por último, aquella escasez de investigaciones sobre el golpe en regiones ha terminado por homologar lo ocurrido en Santiago con el resto del país, invisibilizando las particularidades que poseen los espacios locales.

El primer capítulo del texto tiene que ver entonces con una contextualización histórica del golpe de Estado de 1973. El autor parte evidenciando que la Doctrina de Seguridad Nacional fue un fundamento teórico para la intervención militar, manifestando la existencia de dos fuerzas opuestas, amigo-enemigo, aquella concepción binaria de la sociedad en la cual se identificó a partidos políticos, movimientos sociales y populares como aquellos que ponían en peligro la seguridad nacional. Por consiguiente, lo anterior permitió la participación activa de las fuerzas militares. De esta manera, el Estado de Seguridad Nacional, mediante diversos dispositivos, fue legalizando y legitimando la violencia contra los denominados enemigos internos.

En consecuencia, tanto los Bandos Militares, constituidos como los primeros mecanismos punitivos que buscaron legitimar la acción militar del golpe; los decretos leyes, que sustituyeron en la práctica la tarea del poder legislativo -institucionalización de la violencia-; las actas de la Junta, que fueron las sesiones de trabajo realizadas en las reuniones; los discursos que buscaron legitimar la intervención militar y, por último, la violencia simbólica -psicológica- tuvieron como principal objetivo la interiorización del control social como mecanismo de disciplinamiento.

El segundo capítulo inicia con un breve análisis de los antecedentes de la zona estudiada, dejando entrever la importancia del movimiento obrero desplegado a lo largo de la región en su construcción histórica. Así, el proceso industrializador configuró, o más bien dividió -en el buen sentido del concepto-, al Gran Concepción en cuatro grandes polos de desarrollo obrero: en primer lugar, Lota, Coronel y Lirquén como principales fuentes de extracción del carbón; la loza en Penco; las textiles de Tomé y Chiguayante; y la siderúrgica de Huachipato en Talcahuano. En consecuencia, fue este proceso de industrialización el que incidió de forma directa y desde el punto de vista demográfico, en la fuerte migración campo-ciudad, en la izquierdización y en el surgimiento del Movimiento de Izquierda Revolucionaria (MIR). Por consiguiente, fue necesario para el régimen -la mañana del martes 11 de septiembre de 1973- efectuar un rápido control de la zona.

En la tercera parte de esta investigación, Monsálvez da cuenta de las facetas públicas y sociales del golpe de Estado en Concepción. En consecuencia, inicia este capítulo planteando la siguiente pregunta, ¿cuáles fueron los espacios institucionales y sociales donde la violencia política se hizo sentir con 
mayor fuerza? Para responder, deja en claro la importancia que tuvo para las autoridades del régimen la confección del "libro blanco del cambio de gobierno", debido a que en sus páginas se informaba de la supuesta elaboración de un plan de autogolpe que había estado preparando la izquierda nacional, denominado "Plan Z", el cual, según la dictadura, buscaba eliminar a altos mandos del ejército. De esta manera, el golpe de Estado estaba justificado y se intentaba dar a entender de esa forma a la población.

Para tal efecto, el régimen recurrió al Código de Justicia Militar de 1925, en el cual se estipulaba que, durante el tiempo o estado de guerra, la justicia militar debía ser administrada por consejos de guerra. Por su parte, el Informe Rettig indica que para Concepción se obtuvieron copias de nueve de estos consejos, que juzgaron a 81 inculpados, configurando así un entramado punitivo muy bien elaborado.

De esta manera, la desarticulación de la izquierda y el miedo infundido a la ciudadanía tenían como principal objetivo el disciplinamiento social. Por ende, la dictadura buscó producir un conformismo activo en la población a través de la idea de "nación", y mediante una serie de nuevos valores, como la despolitización -proscripción de los partidos políticos y prohibición de reuniones-y la normalización de las conductas (p. 116). Para tales efectos, fue fundamental para la dictadura la intervención y despolitización de la Universidad de Concepción, aquella que en la década de 1970 había sido considerada una institución comprometida con los procesos sociales de la época, siendo catalogada bajo el epíteto de "universidad roja". De esta forma, se procedió el cierre de la Escuela de Periodismo, sindicada como uno de los principales focos del mirismo al interior de la universidad. Le siguió la de sociología, básicamente por constituirse, según las nuevas autoridades, en un centro o espacio que solo servía para la subversión.

Sin embargo, Monsálvez presta mayor énfasis a los exiliados, definiendo incluso teóricamente el concepto, para luego dar una mirada en plano nacional y local. No obstante, no se detiene a analizar en sus páginas lo relacionado con la relegación ocurrida en la zona, la que al igual que las demás prácticas punitivas se han desarrollado desde el siglo XIX.

El último capítulo dice relación con las voces públicas del golpe de Estado. Específicamente, Monsálvez pone la mirada en el papel de la prensa escrita en Concepción. De esta manera, con el objeto de entender la acción de dicha prensa, el autor centra su análisis en dos líneas: en primer lugar, la difusión de los discursos políticos que van más allá de una visión institucional y, en segundo término, la construcción de hegemonía, ya que ambas buscaron mantener el control de todo el discurso público con el cual pudiesen avanzar en la persuasión o elaboración del consenso (p. 165). 
En consecuencia, nos preguntamos, ¿por qué la dictadura recurrió a la prensa para lograr modelar las conductas de la población luego de ocurrido el golpe de Estado de 1973? Para dar respuesta a lo planteado, Monsálvez manifiesta que la información produce poder y este poder se reproduce mediante estructuras informativas. Sin embargo, citando a van Dijk, deja en claro que este poder debe ser entendido en términos discursivos, ya que, controlando las mentes de las personas, se puede controlar indirectamente sus acciones (p. 167). Surge entonces: una segunda interrogante ¿qué extrajo el autor de los medios de prensa estudiados? Aquellos discursos políticos que giran en torno a los conceptos de "orden", "disciplina", "progreso", "jerarquía", "respeto" y "normalidad"; visibilizados en tres temas, en las editoriales de cada periódico y revistas de la época, las columnas de opinión y los avisos e inserciones de estos.

En las columnas de opinión, por ejemplo, fue común encontrar la expresión de sectores de la sociedad de Concepción que respaldaron el golpe de Estado y las acciones que impulsó la Junta Militar. Quienes escribieron, lo hicieron sobre la justificación del golpe, destacando y apoyando ciertos valores y actitudes de las Fuerzas Armadas.

De esta manera, se desprende de la investigación que los medios de prensa fueron fundamentales en los primeros años de dictadura para lograr controlar y normalizar a la población, para luego trazar los objetivos y metas que estos querían alcanzar.

Concluyendo, las dos interrogantes que intentó responder autor a lo largo de sus páginas, dicen relación con el debate acerca de: 1- ¿Cuándo surgió la violencia política en la Historia Reciente de Chile? 2- ¿Son comparables los hechos de violencia ocurridos antes y después del golpe de Estado de 1973?

Finalmente, este trabajo viene a evidenciar, por un lado, que la violencia política no surgió con la aparición del discurso de la izquierda, como lo ha manifestado Patricia Arancibia, y, por otro, que dicha violencia, si bien existió desde comienzos del siglo XIX, fue durante la dictadura cívico-militar que se institucionalizó y se volvió mayormente selectiva y represiva. Para demostrarlo, el autor centró su estudio en la ciudad de Concepción, dejando entrever que la excepcionalidad en materia de represión fue resultado de una imagen que el país tenía de la ciudad hasta antes del 11 de septiembre de 1973, el de una zona marcada por la presencia de la izquierda, convirtiendo a la localidad en la segunda zona del país más castigada, y siendo, después de Santiago, el lugar con mayor número de víctimas producidas por la represión militar.

Por último, es difícil criticar este tipo de trabajos que, por las escasas investigaciones realizadas sobre el tema y lugar, más bien aportan a la construcción de nuestro pasado reciente local; además, es entendible que 
el autor no se pueda hacer cargo en un volumen de tantos temas pendientes. Lo significativo entonces es que a partir de este trabajo surgen nuevas interrogantes a tratar. Sin embargo, los relatos testimoniales estuvieron algo ausentes y en una investigación que dice relación con nuestro pasado cercano es fundamental la presencia de estos.

Javier González Alarcón'

\section{Referencias bibliográficas}

Monsálvez, D. (2012). "Violencia y represión en un dispositivo local: Concepción, 11 de septiembre de 1973", en Revista de Historia y Geografía, N²6, pp. 57-80.

1 Chileno. Licenciado en Historia, Universidad Nacional Andrés Bello y Magíster en Historia, Universidad de Concepción, Chile. E-mail: mrsydbarret1@gmail.com 